\title{
Persian Turquoise: The AnCIent Treasure OF NeYshabur
}

Bahareh Shirdam, Andy H. Shen, Mingxing Yang, Zahra Mokhtari, and Hamed Fazliani

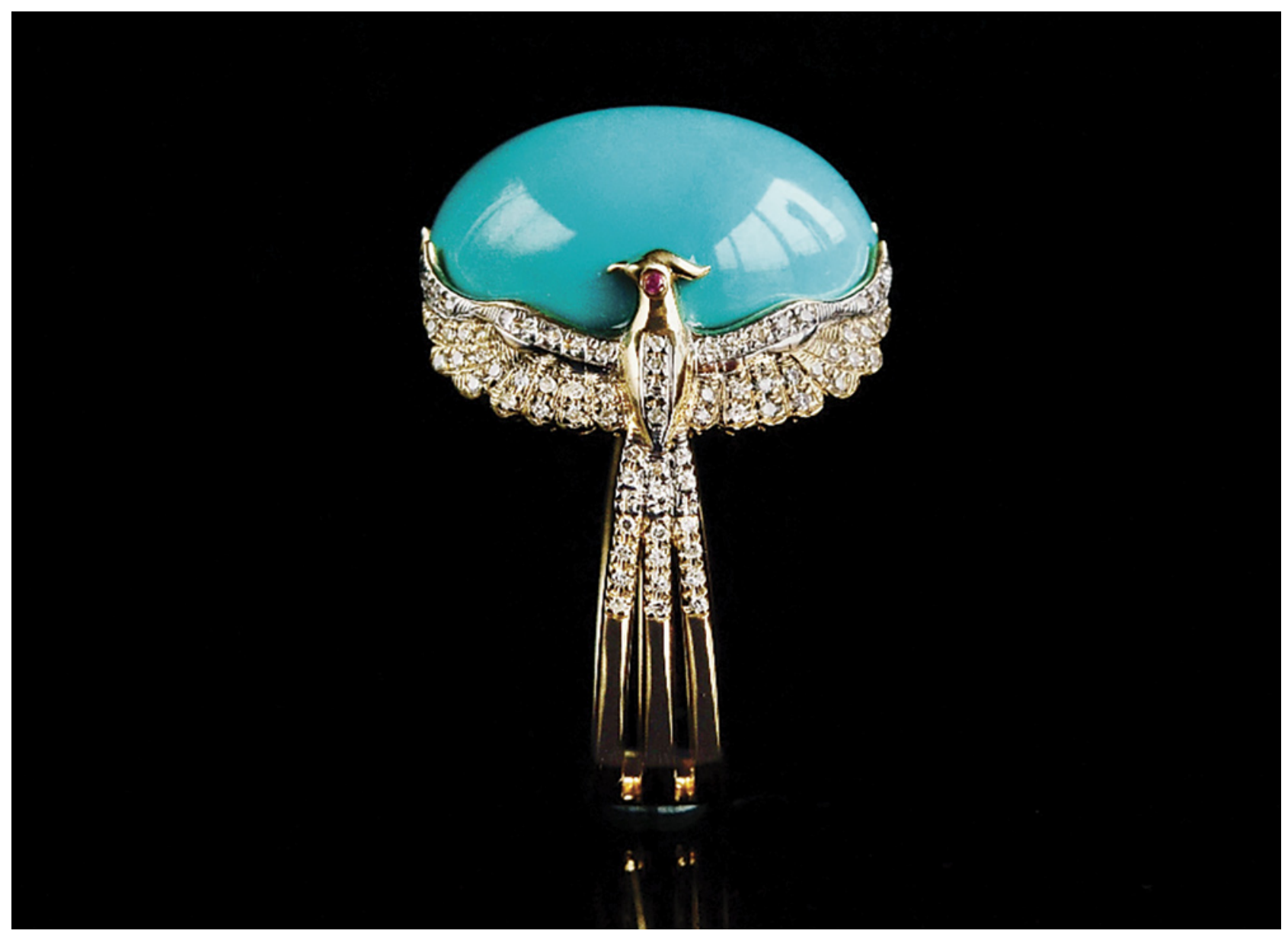

Figure 1. This gold ring with a phoenix motif features a Neyshabur turquoise $(13 \times 17 \mathrm{~mm})$, with a $0.02 \mathrm{ct} \mathrm{ruby} \mathrm{on}$ each side and diamond accents. Courtesy of Taktala Jewelry, Tehran.

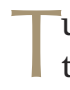

urquoise is an opaque, blue to green gem material that has been worn, used, and appreciated by different civilizations for thousands of years. Originally called piruzeh in Persian, the gem has spiritual value in Persian culture is such that its name carries the meanings of victory, triumph, and prosperity. In Per-

See end of article for About the Authors and Acknowledgments.

Gems \& Gemologr, Vol. 57, No. 3, pp. 240-257,

http://dx.doi.org/10.5741/GEMS.57.3.240

(C) 2021 Gemological Institute of America sian literature, turquoise has been celebrated by poets, and various legends and beliefs are associated with it (Vinogradov et al., 1966).

Archeological discoveries from the Deh Luran Plain in western Iran indicate that turquoise was first utilized around 7000 BCE (Hole et al., 1969). The quantity of turquoise artifacts discovered in burial sites suggests the importance of this mineral in this ancient civilization's traditions. While the estimated age of these artifacts is valid, no scientific study has linked them to any specific deposit. 
TABLE 1. Deh Luran Plain zones with evidence of turquoise ornaments.

\begin{tabular}{cccc}
\hline Period & Chronology & Zone & Province \\
\hline \multirow{2}{*}{ Neolithic } & 7000 BCE & Ali Kosh & Ilam \\
& 6500 BCE & Mohamad-Djaffar & Ilam \\
\hline
\end{tabular}

The Neyshabur (Latinized as Nishapour) deposit is known for yielding turquoise with unique color and quality. This production has historically been known as "Persian turquoise" (figure 1), yet Iran's turquoise deposits were never limited to Neyshabur. Other important mines include the Baghu deposit in southern Semnan Province and the Shahr-i Babak deposit in western Kerman Province, the latter of which was mentioned in Marco Polo's Book of the Wonders of the World between 1390 and 1430 (Weisgerber, 2004).

Located in the Razavi Khorasan Province of northeastern Iran, $53 \mathrm{~km}$ from the city of Neyshabur, the Neyshabur mine has produced the majority of Iranian turquoise for more than a millennium. Yet in recent decades there have been claims that the mine is on the verge of closure, that its turquoise quality has diminished, or that it is running out of material. Such claims often carry enormous weight with con- sumers. After visiting the Neyshabur turquoise mine in 2020, a report was conducted on the current state of the mine. This article seeks to uncover the facts and offer objective insight on the current state of the Neyshabur turquoise mine.

According to Hole et al. (1969), the earliest Persian turquoise artifacts were discovered in the Deh Luran Plain in western Iran. Radiocarbon dating suggests that turquoise beads found in burial sites from the Ali Kosh and Mohamad-Diaffar zones date back to 7000 BCE and $6500 \mathrm{BCE}$, respectively (table 1).

These turquoise ornaments came in various forms such as beads, pendants, and piercings. The most interesting group of turquoise beads was associated with one of the burials from the MohamadDjaffar zone, where two beads and a piercing referred to as a labret were found (figure 2). The highly polished beads were found near the neck, and the labret lay near the breastbone.

Figure 2. A: Turquoise ornaments associated with a burial in the Mohamad-Djaffar zone. On the top and bottom are beads, possibly from a pendant, while the middle ornament is a piercing referred to as a labret. B: The position of the turquoise artifacts in the burial. C: An actual photo of the burial. These images from Hole et al. (1969) are used with permission of the University of Michigan Museum of Anthropological Archaeology.

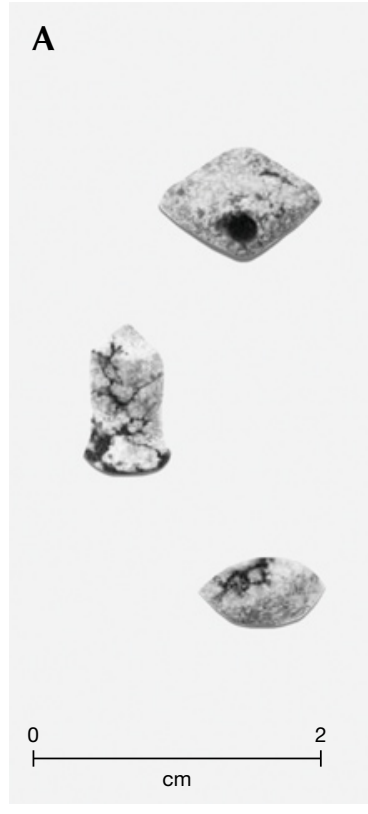

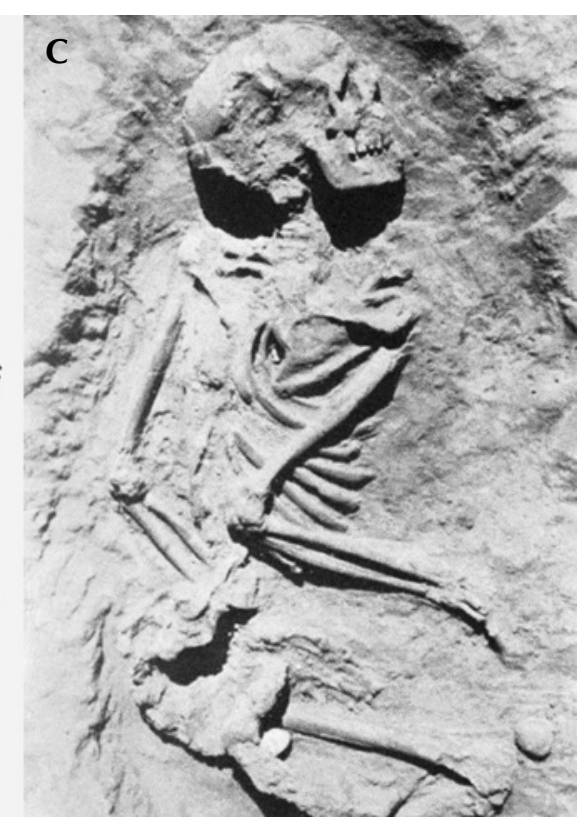



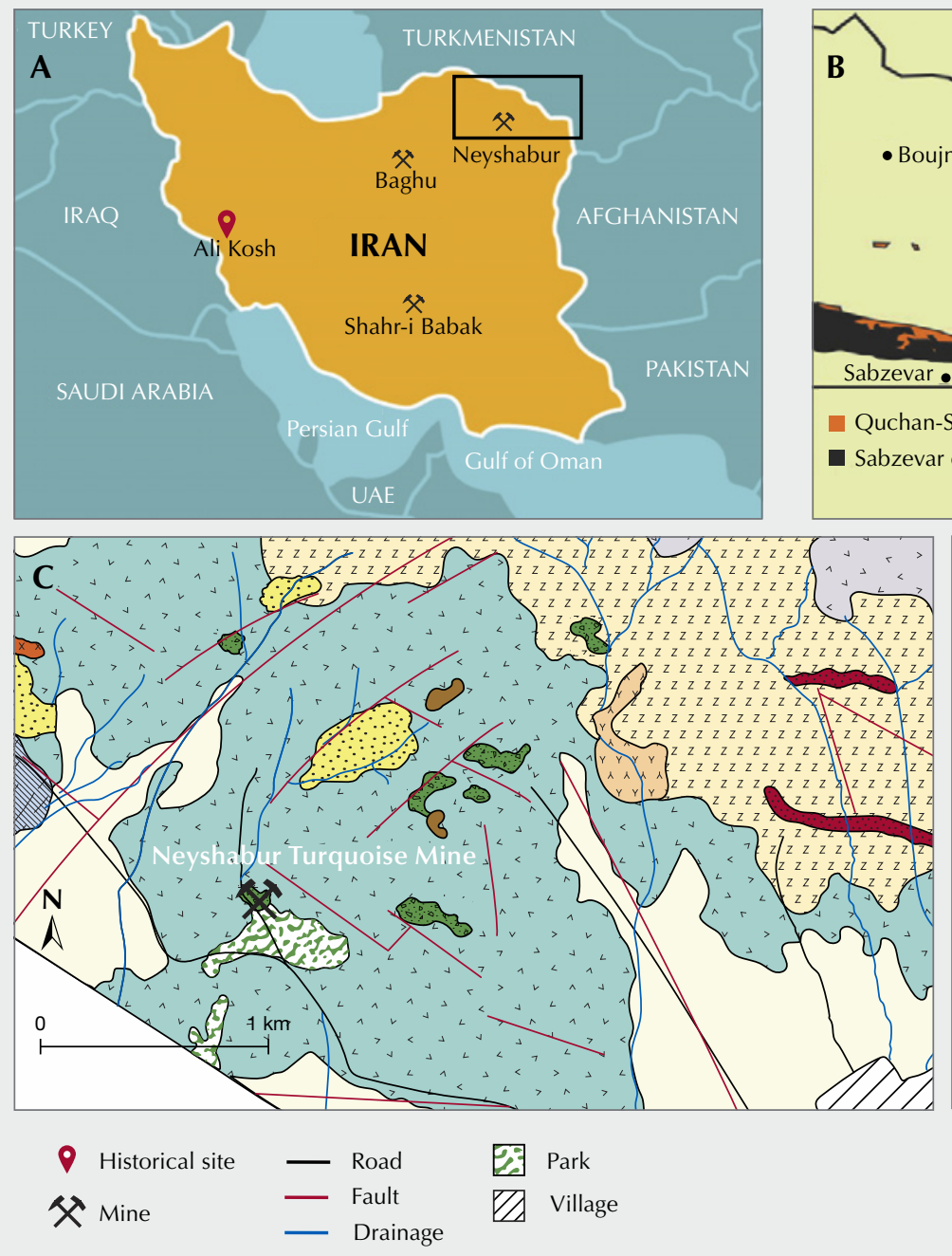
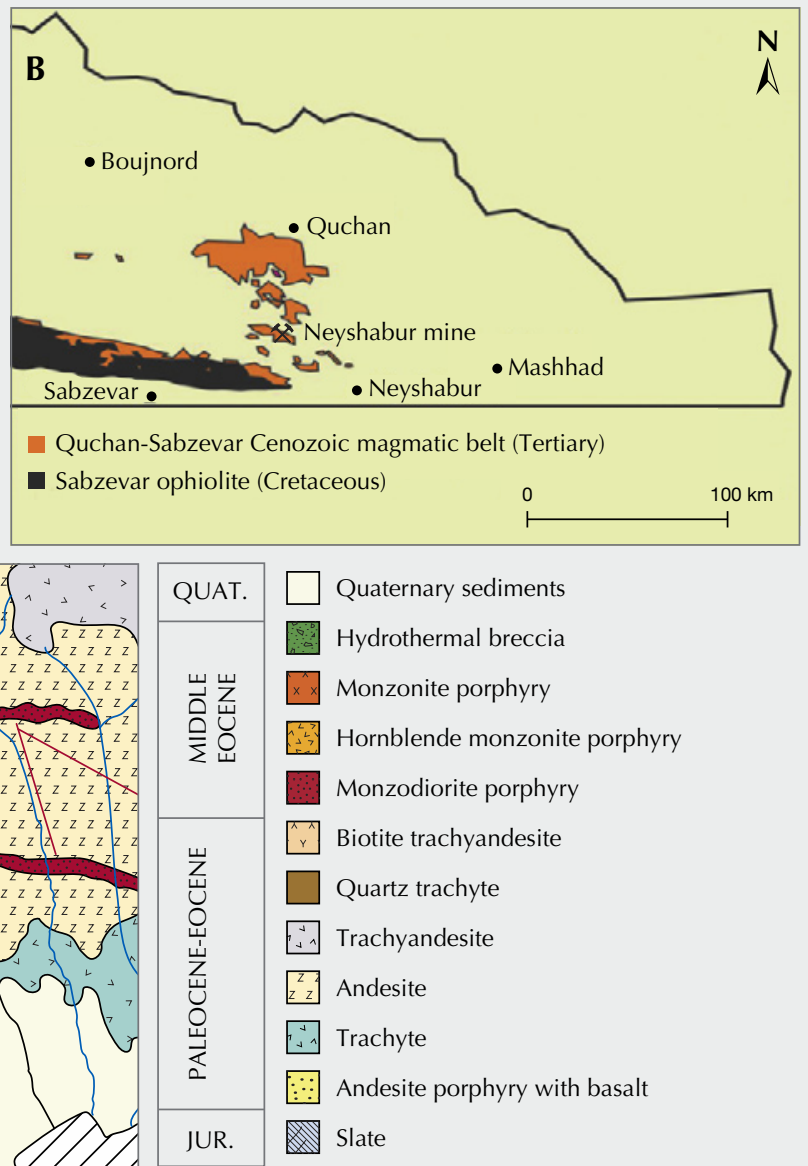

Figure 3. A: Locations of Iran's main turquoise mines. B: The Quchan-Sabzevar magmatic belt (Eshbak et al., 2019). C: Geological map of the Neyshabur mine, 1:10000 scale (Ghiasvand et al., 2017).

It should be noted that turquoise has not been known to occur in the Mohamad-Diaffar zone, which is part of the Ali Kosh historical site (figure 3A). The closest possible source is at least $900 \mathrm{~km}$ away.

\section{LOCAL GEOLOGY}

The Neyshabur turquoise mine is located at the far east end of the Quchan-Sabzevar magmatic arc (figure 3B). This arc in northeastern Iran indicates a complex tectonic-magmatic evolution and is characterized by extensive magmatic activity with a range of geochemical signatures. Magmatic activities started there during the Cretaceous, peaking during the Eocene (40 Ma) and then continuing into the Plio-
Pleistocene (2 Ma). The volcanic and plutonic rocks of the arc can be divided into three groups (Spies et al., 1984), including Eocene intermediate igneous rocks, Oligocene acidic igneous rocks, and MiocenePleistocene alkaline basalts.

Major rock units of the Neyshabur mine are divided into three groups: volcanic, subvolcanic intrusions, and hydrothermal breccia (Ghiasvand et al., 2017). Although the volcanic rocks of trachyte and andesite are most widespread in the area (figures 3C and 4), subvolcanic intrusions such as monzosyenite and monzodiorite have outcrops inside the mine. Primary minerals of volcanic and subvolcanic units include pyrite, magnetite, specularite, chalcopyrite, 


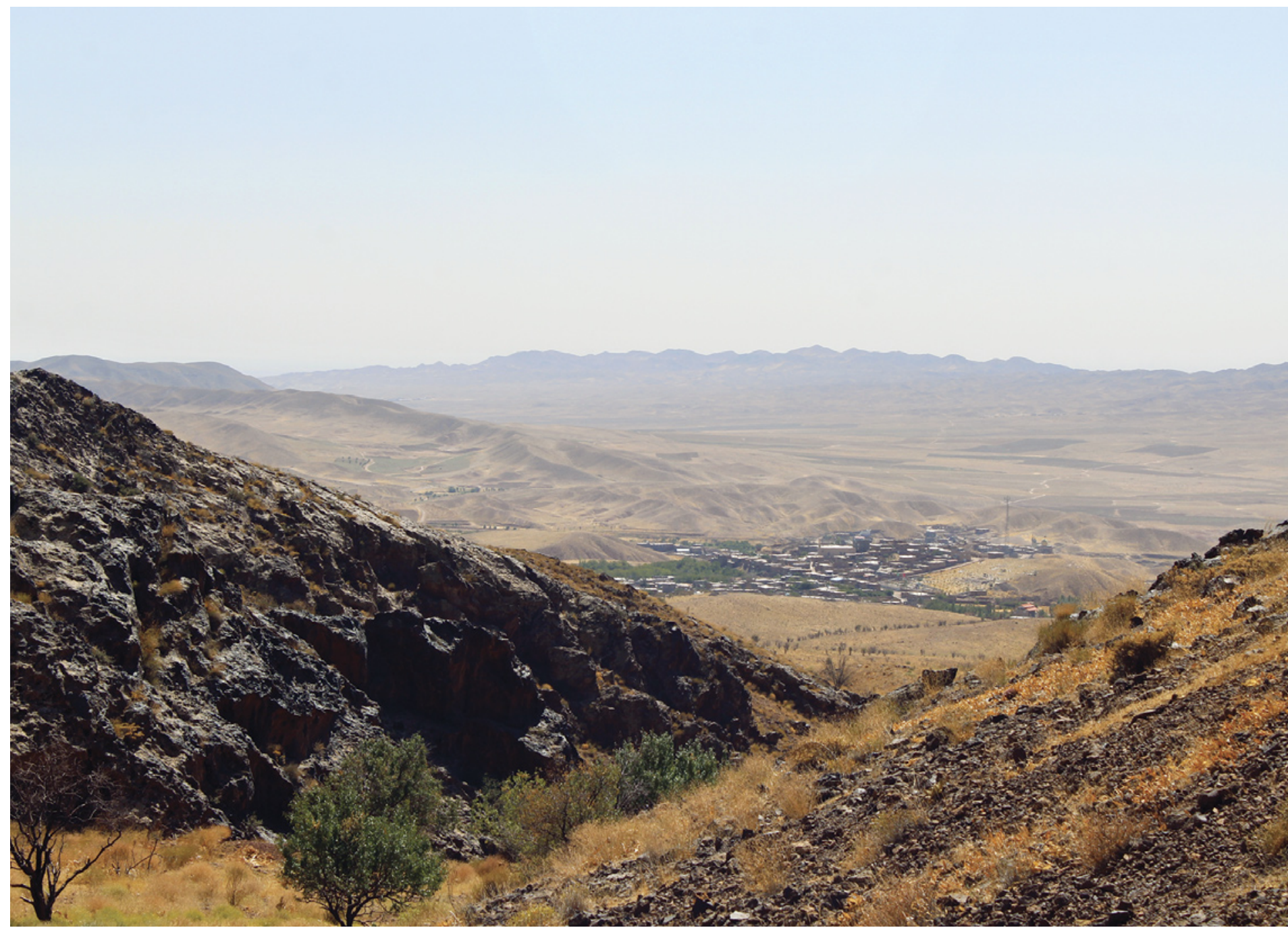

Figure 4. A volcanic mass outcrop in the eastern part of Raish Mountain. The village of Ma'adan is visible in the center. Photo by B. Shirdam.

and bornite. Secondary minerals are turquoise, chalcocite, hematite, covellite, and goethite.

\section{THE NEYSHABUR TURQUOISE MINE}

Previously owned by various organizations, the Neyshabur turquoise mine became a cooperative in 2003. It is currently owned by shareholders who are all residents of Olia and Sofla, the two parts of $\mathrm{Ma}^{\prime}$ adan village (figure 4). Some of these shareholders work in the mine, while the rest manage businesses related to cutting or selling.

The mine is located at Raish Mountain, where turquoise has been recovered for millennia. Traditionally, wherever a turquoise vein was exposed on the mountain surface and its value was recognized, the vein would be followed down into the ground by either strip mining or digging short tunnels.

Another technique, deep-vein mining, was the most difficult and dangerous in centuries past. Whereas once only gold and silver were considered valuable enough to justify digging underground in other parts of the world, turquoise carried such importance in Persian culture that some deep shafts in the mountain date back many centuries. After a suitable site was found, tunnels were excavated in the rock to remove the vein. Narrow vertical shafts were driven through the rock, widening out to horizontal galleries where the ore was found. Sometimes hori- 


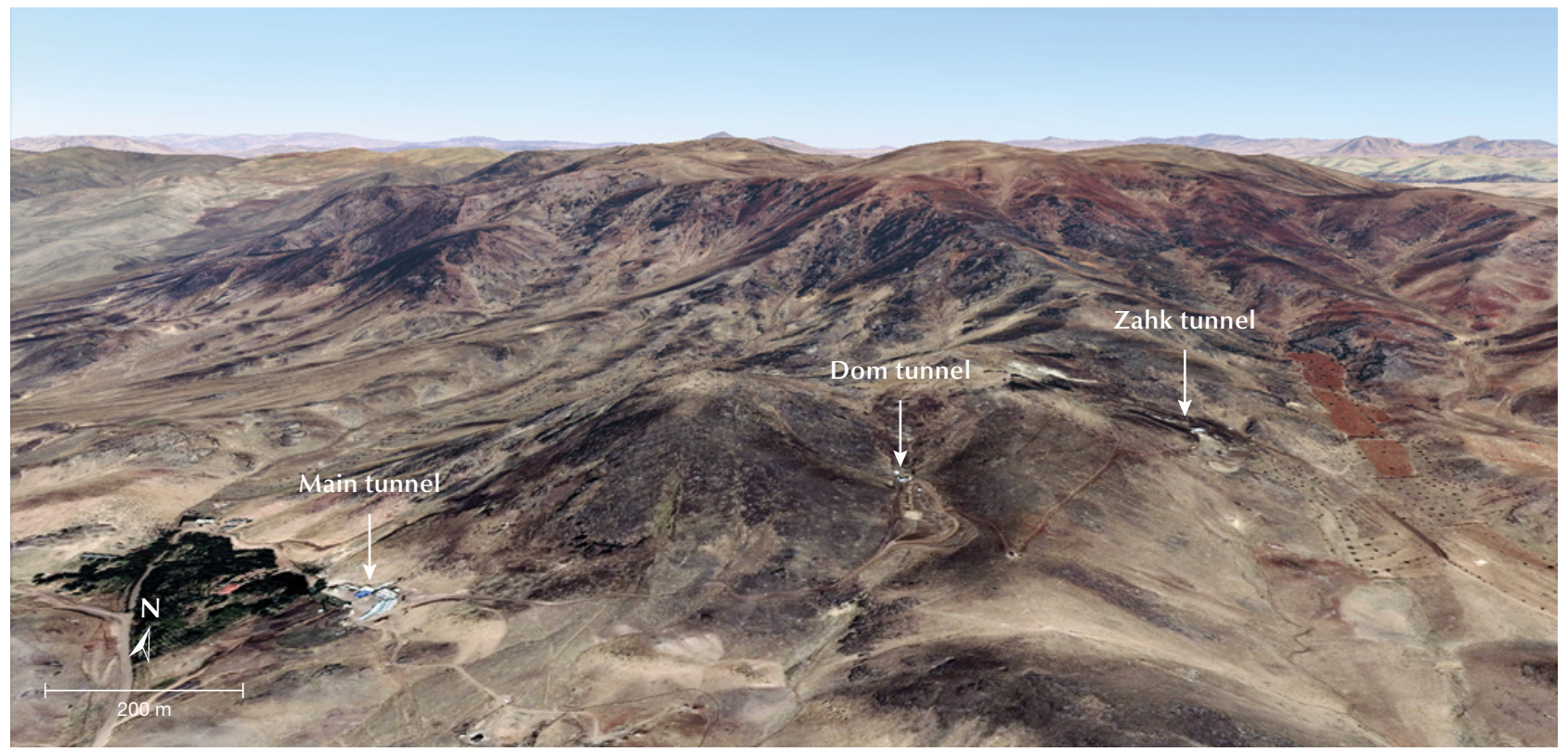

Figure 5. 3D image of Raish Mountain and the Neyshabur mine's three principal tunnels. The compass arrow points north. From Google Earth.

zontal adits ${ }^{1}$ from a hillside were driven as well. Working below ground, the miners had to deal with the need for lighting and the dangers of poor ventilation. Some of these old mining operations are still standing, while others have collapsed.

Today the Neyshabur turquoise mine consists of three active tunnels, shown in figure 5: $\mathrm{Main}^{2}$, Dom, and Zahk. Each will be discussed separately.

Main Tunnel. The Main tunnel consists of four major active tunnels: Chah Abdar ${ }^{3}$, Ardalani, Sabz ${ }^{4}$, and Rokub. Starting from the Main tunnel (main drift ${ }^{5}$ ) (figure 6), the first crosscut leads to the mine's shaft and the downward path to Chah Abdar (figure 7). The shaft, a vertical passageway for ventilation and material transport, is equipped with a hoist and extends 80 $\mathrm{m}$ underground. At regular intervals along the shaft, horizontal openings are driven toward turquoise layers that lie 11 levels $^{6}$ below the main drift. Chah Abdar is on the lowest level of the mine, reaching groundwater that leaks into the tunnel. The manway path for accessing Chah Abdar is constructed of downward stairs (figure 8), ramps, and winzes ${ }^{7}$.

The first and second access tunnels are called Ardalani and Sabz, respectively (figure 6). They have active stopes ${ }^{8}$ and raises ${ }^{9}$ ascending to nine active floors, $30 \mathrm{~m}$ above the main drift. The raises are excavated in the form of an inclined path or manway ladders (figure 9). The Main tunnel, more than $2 \mathrm{~km}$ in length, is not only used as a transport drift but also has stopes on its path. The Rokub tunnel is actually part of the Main tunnel. It begins around $700 \mathrm{~m}$ from the tunnel's entrance and covers such a large area that it has been divided into Rokub I and Rokub II (figure 7).

One characteristic of the Neyshabur mine is the height variation of its tunnels. This is most obvious in the Main tunnel, which begins at $1.5 \mathrm{~m}$ high and gradually increases to $3 \mathrm{~m}$ or higher, where old stopes were excavated.

The rock units exposed in the Main tunnel can be divided into volcanic units, hypabyssal intrusive rocks, and hydrothermal breccia (Ghiasvand et al., 2017). Volcanic rocks, including trachyandesite and

\footnotetext{
${ }^{1}$ Horizontal passages driven from the surface into the side of mountain. ${ }^{2}$ The tunnel's original Persian name, "Asli," literally translates to "Main."

3Persian for "water well."

${ }^{4}$ Persian for "green."

${ }^{5} \mathrm{All}$ horizontal or subhorizontal openings made in a mine are generically known as "drift."

${ }^{6}$ Horizontal openings on a working horizon in a mine.

${ }^{7}$ Vertical connections between different levels driven from an upper level downward.

${ }^{8}$ Openings made in the process of extracting ore and minerals.

${ }^{9}$ Vertical connections between different levels driven from a lower level upward.
} 


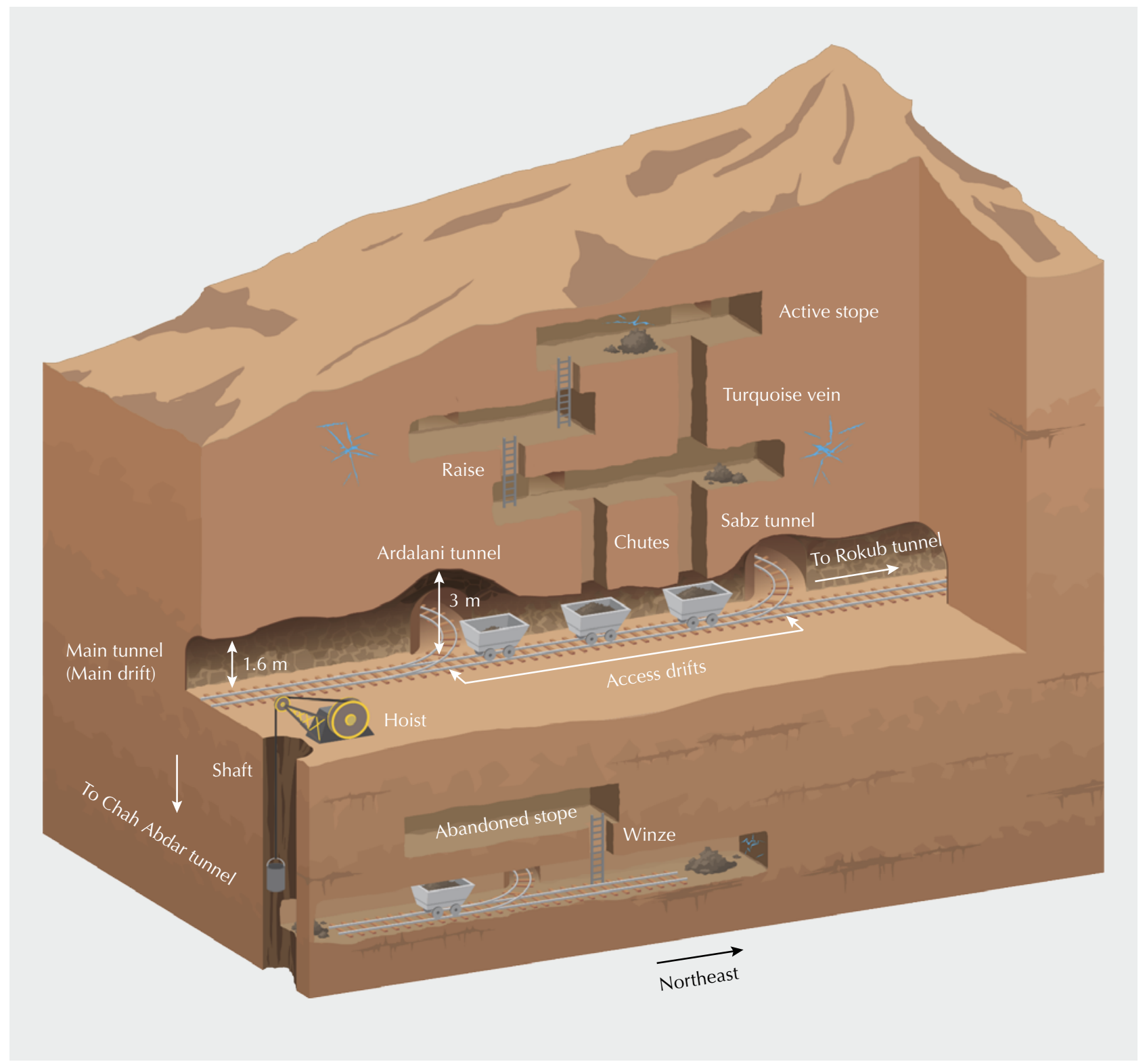

Figure 6. Schematic view showing part of the Neyshabur underground turquoise mine.

andesite, occupy a large part of the Main tunnel. The texture of these bedrocks is porphyritic and their matrix is mainly fine-grained. Subvolcanic intrusive rocks with a combination of quartz monzosyenite porphyry and monzodiorite porphyry are exposed in the Sabz tunnel. The texture of these rocks is porphyritic with a medium-grained matrix.

A hydrothermal breccia unit is observed in the beginning of the Main tunnel and in the downward path to Chah Abdar (figure 6). The existence of different geological units, host rocks, and elemental anomalies causes variation in turquoise color and quality. For example, veins from the Sabz tunnel's stope have a significant greenish color (figure 10), while turquoise from Ardalani's upper level exhibit a blue color (figure 11).

Dom Tunnel. This name is short for the Persian dovom, meaning it is the second tunnel. As shown in figure 12, Dom is located $70 \mathrm{~m}$ above the main tunnel. There are nine levels above and three levels below the Dom tunnel's entrance level. 

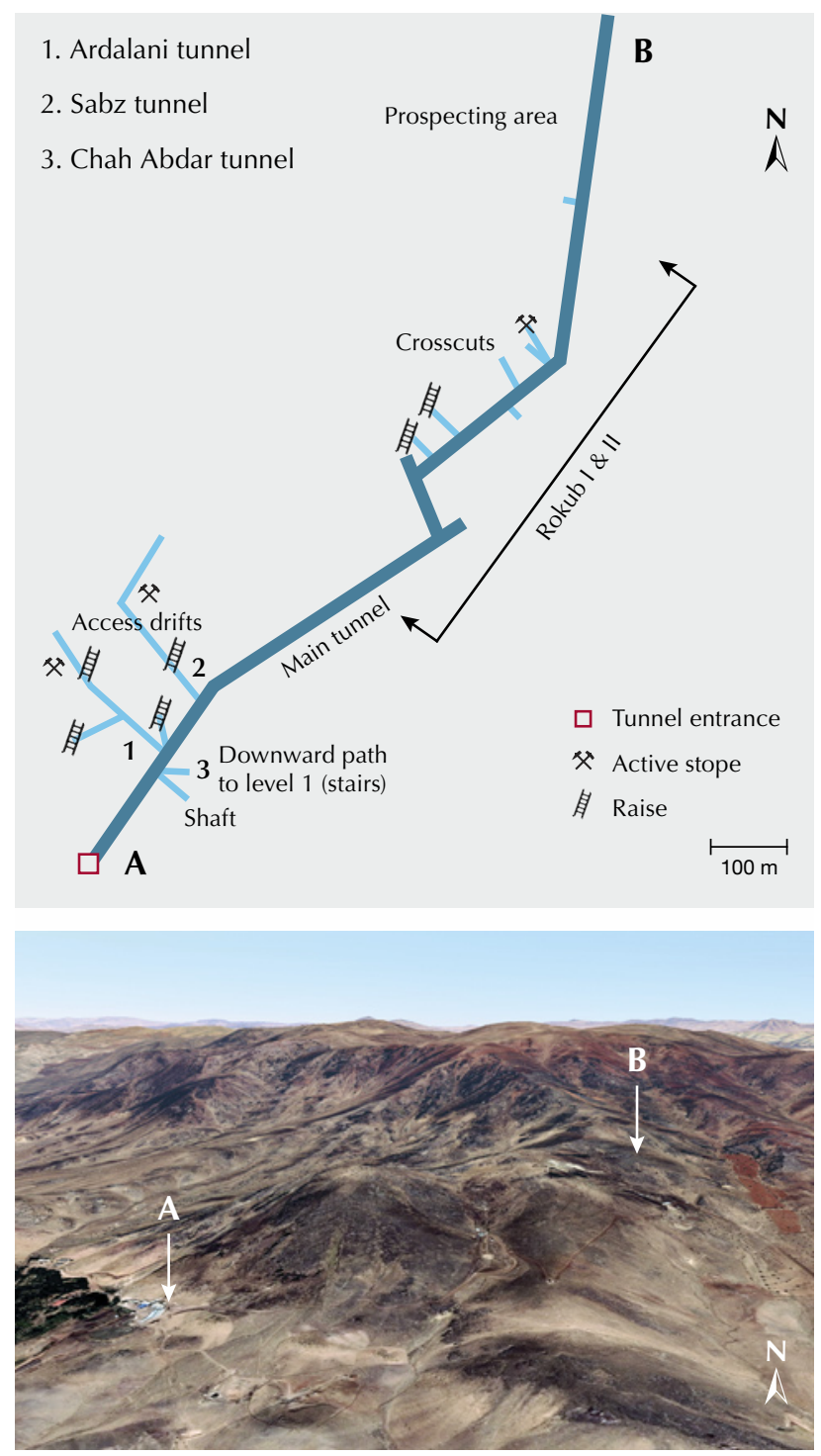

Figure 7. In this map of the Main tunnel, $A$ is the entrance and $B$ is the end of the tunnel. The compass arrow points north.

The same geological units of the Main tunnel are observed in this one, though volcanic rocks and specifically andesite are more widespread. Subvolcanic intrusive rocks are highly altered in this tunnel.

Thick veins of turquoise (figure 13) were observed in the stopes, but most significant was the array of differently colored turquoise observed together (figure 14) in the upper floors of the tunnel. Signs of older mining activities were observed in many places, where the roof was unusually high and later backfill of the stope had caused a slightly steep slope (figure 15).

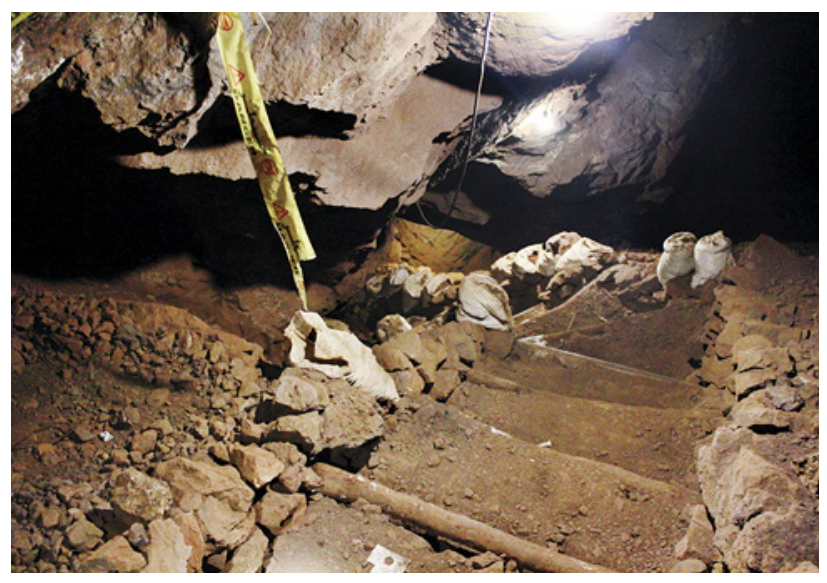

Figure 8. The winze path down to the Chah Abdar tunnel. Photo by B. Shirdam.

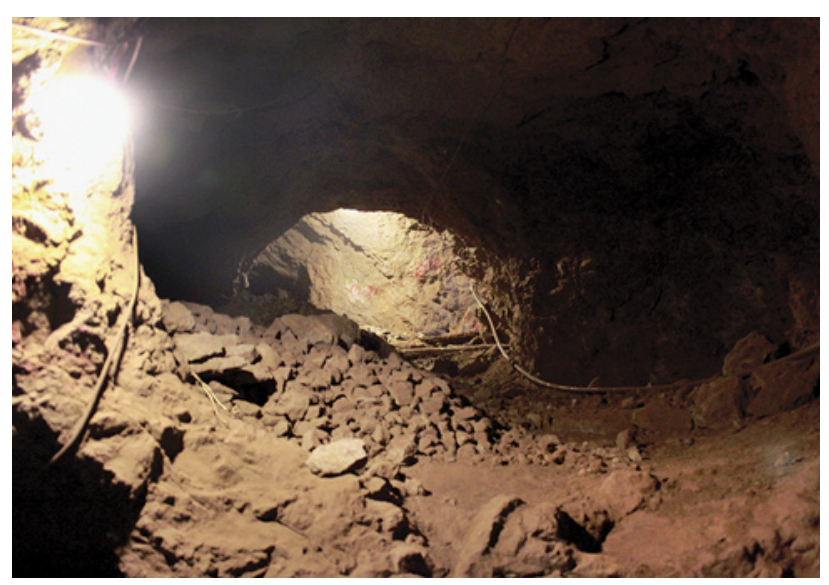

Figure 9. A raise in the form of an inclined path up to the higher levels. Photo by B. Shirdam.

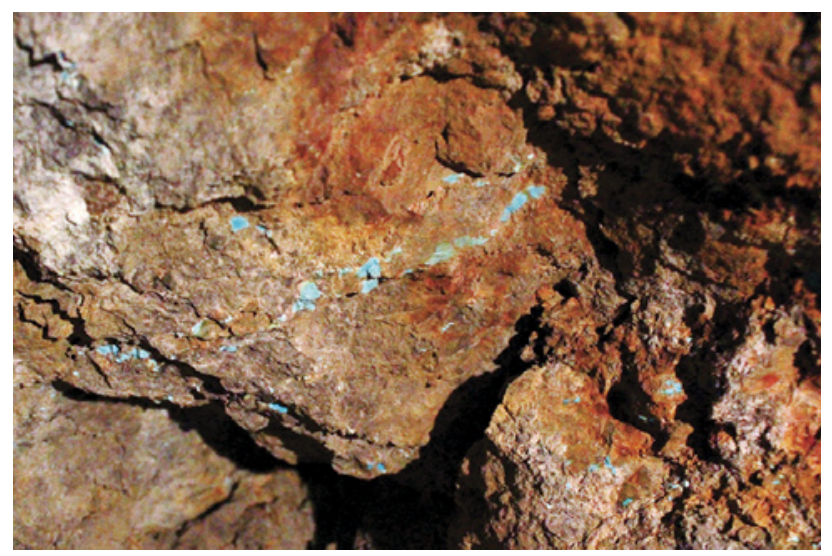

Figure 10. A turquoise vein from the Sabz tunnel's stope. Photo by B. Shirdam.

While smaller than the Main and Zahk tunnels, Dom is the most difficult to navigate. Even though we 


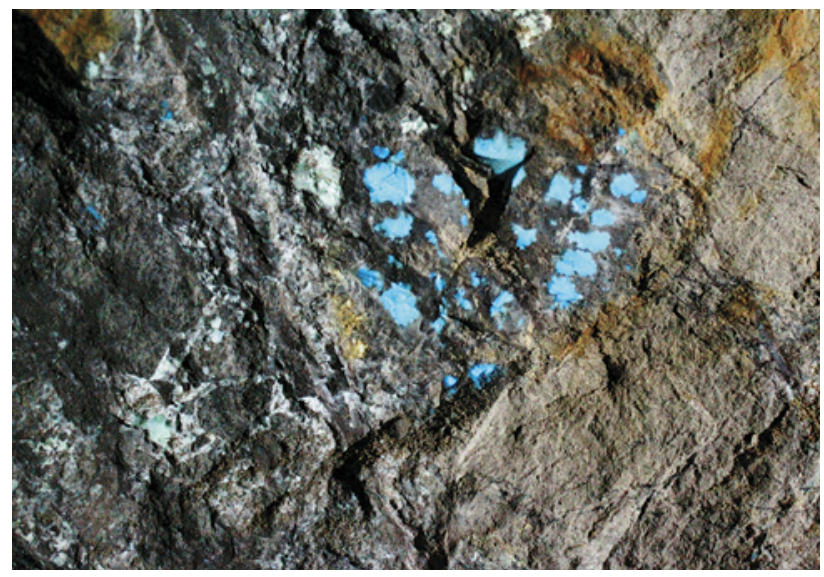

Figure 11. Turquoise from the third level above the Ardalani tunnel. Photo by B. Shirdam.

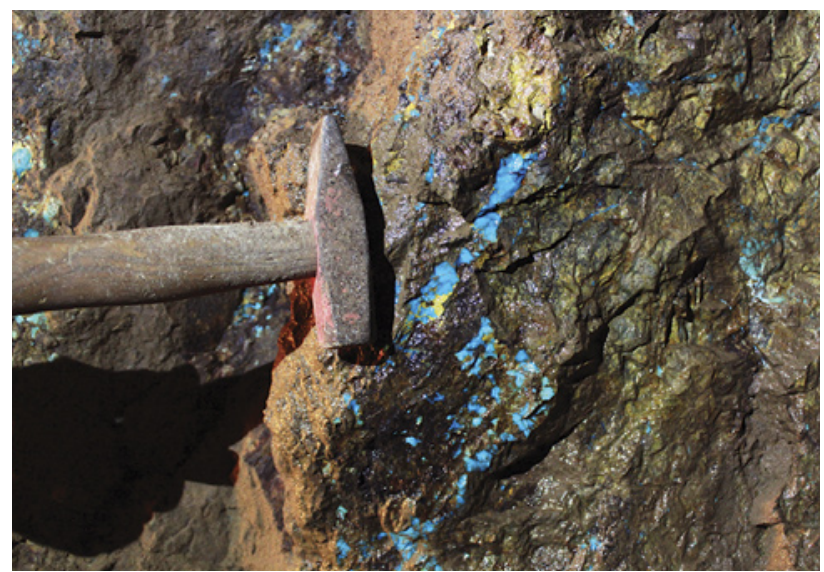

Figure 13. Thick vein of turquoise from the Dom tunnel. Photo by B. Shirdam.

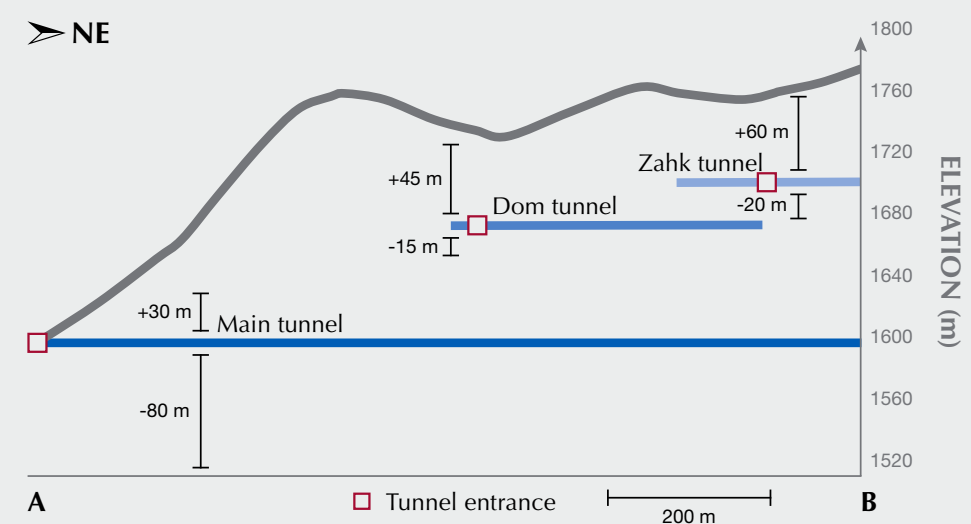

Figure 12. Cross section of Raish Mountain and the positions of the three main tunnels.

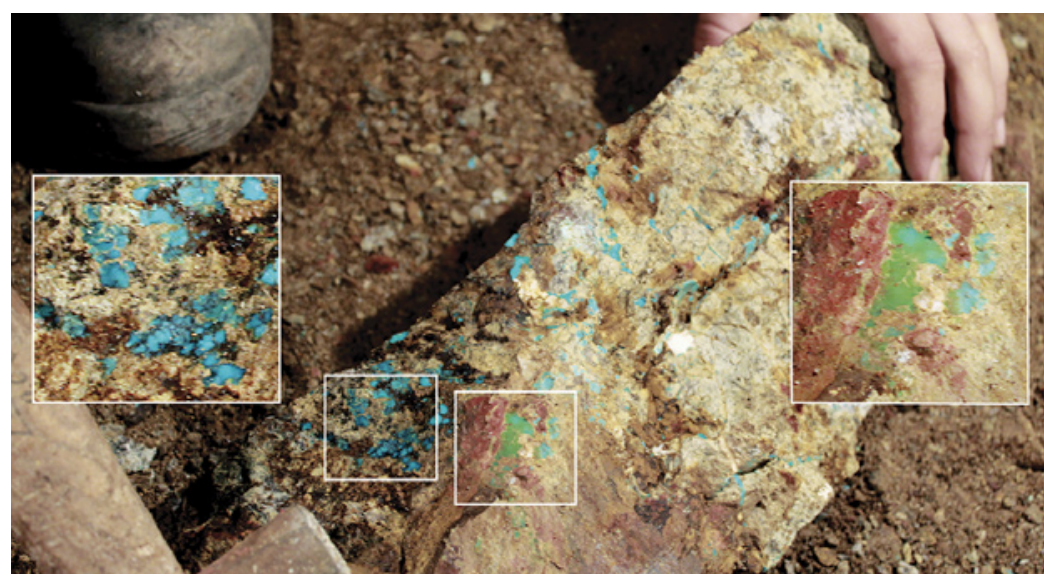

Figure 14. An array of blue to green turquoise colors. Photo by B. Shirdam.

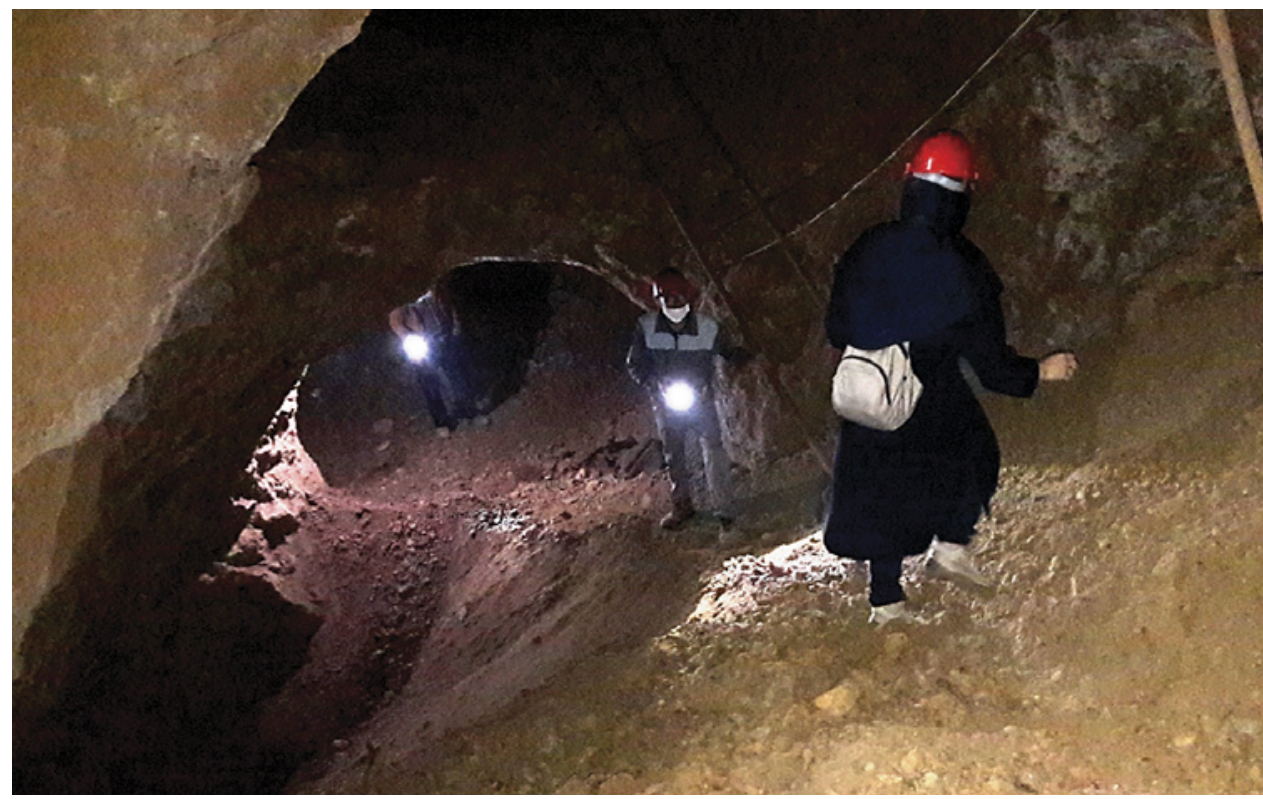

Figure 15. An old stope that has been backfilled to create a path for miners. Photo by $R$. Shirdam. 


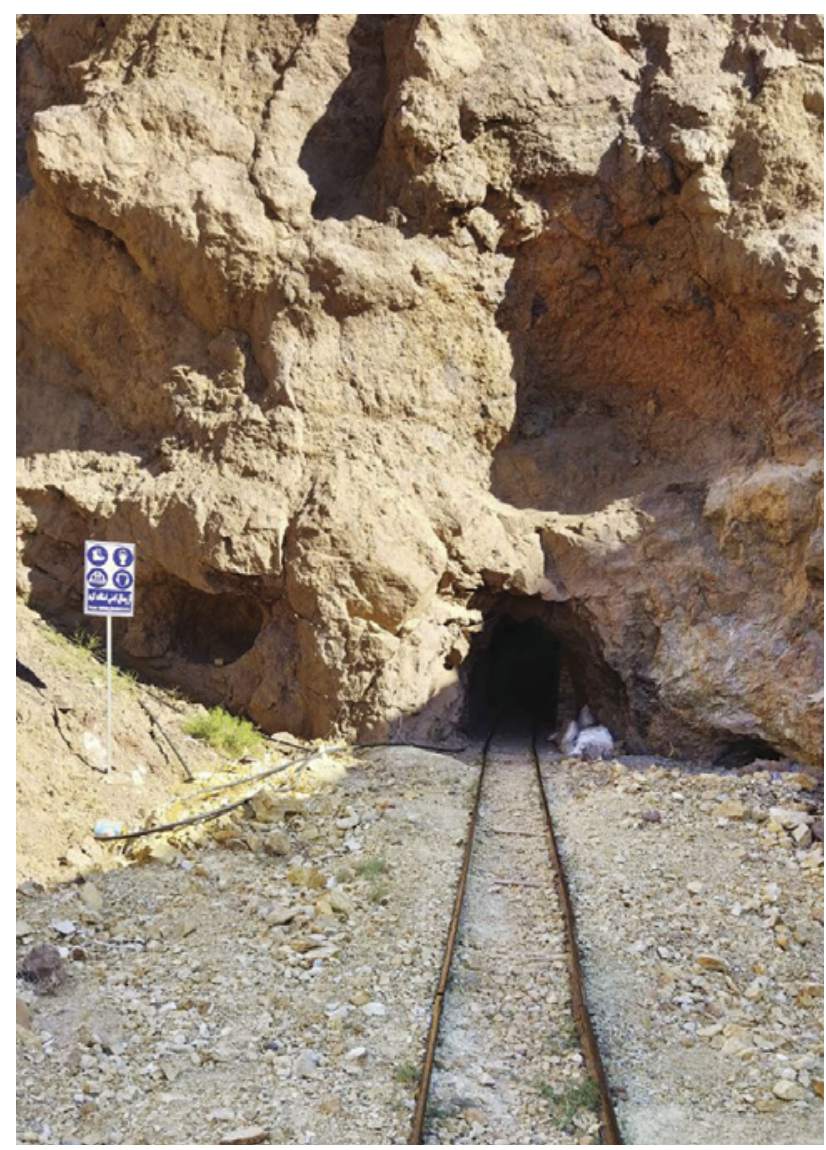

Figure 19. The Khoraj exploration tunnel is located in the south of the mine, and it is expected to join the mine's network below the Main tunnel. Photo by R. Farkhari.

system applied in the Neyshabur mine. This is considered a variant of the room-and-pillar system shown in figure 20A, with a notable difference in the location and order of pillars. Wherever turquoise veins are observed, a stope is excavated, leaving the mine's untouched material working as pillars. When the stope's roof contains numerous turquoise veins, Neyshabur's stope-and-pillar system changes to cut and fill, in which the stope's floor is filled with a layer of mine waste material.

Stoping, the process required for extracting turquoise veins, is conducted by drilling and blasting. Every working day, after the miners have left, the drilling crew enters the tunnels, drilling blast holes inside the walls (figure 21). To minimize damage to turquoise veins, the number of blast holes is limited and their distance from the veins is controlled. As this is a primary deposit with hard host rocks, pneumatic drilling is carried out using compressed air to drive a rotating percussion drill bit. The compressed air generated is distributed across the mine via an extensive piping network (figure 22).

After the drilling crew leaves the tunnels, the blasting crew begins their work, inserting predetermined amounts of explosives into the drill holes. After the mine's complete evacuation, the blasting is carried out and the mine is left to ventilate blast fumes until the next morning. The next day, any wall or stope where work is to be performed is examined for cracks or other signs of stress or weakness.

Ventilation. Ventilation in the mine is mostly natural. As a result of centuries of traditional mining, many deep shafts and openings connect the mountain's surface to the tunnels. The depth of these old shafts reaches to more than $80 \mathrm{~m}$ in some places. Due to the temperature difference between the

Figure 20. Comparison of the more orderly room-and-pillar mining system (A) and the irregular distribution of the stope-and-pillar system used at Neyshabur (B).

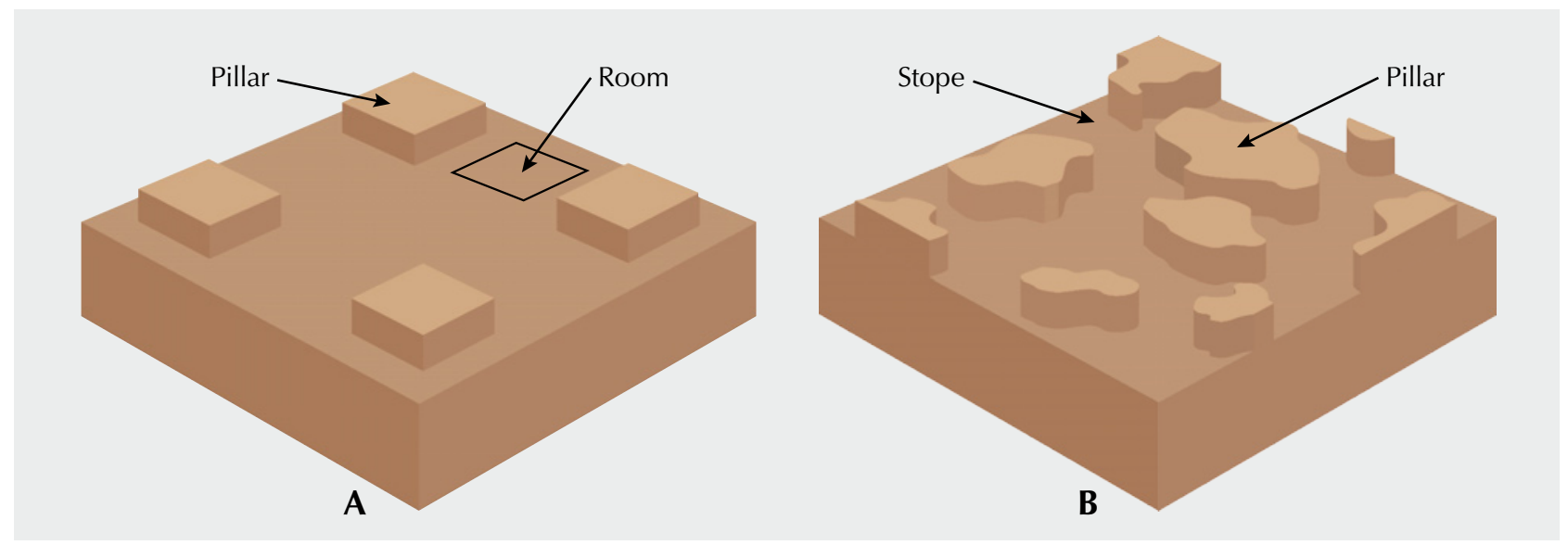




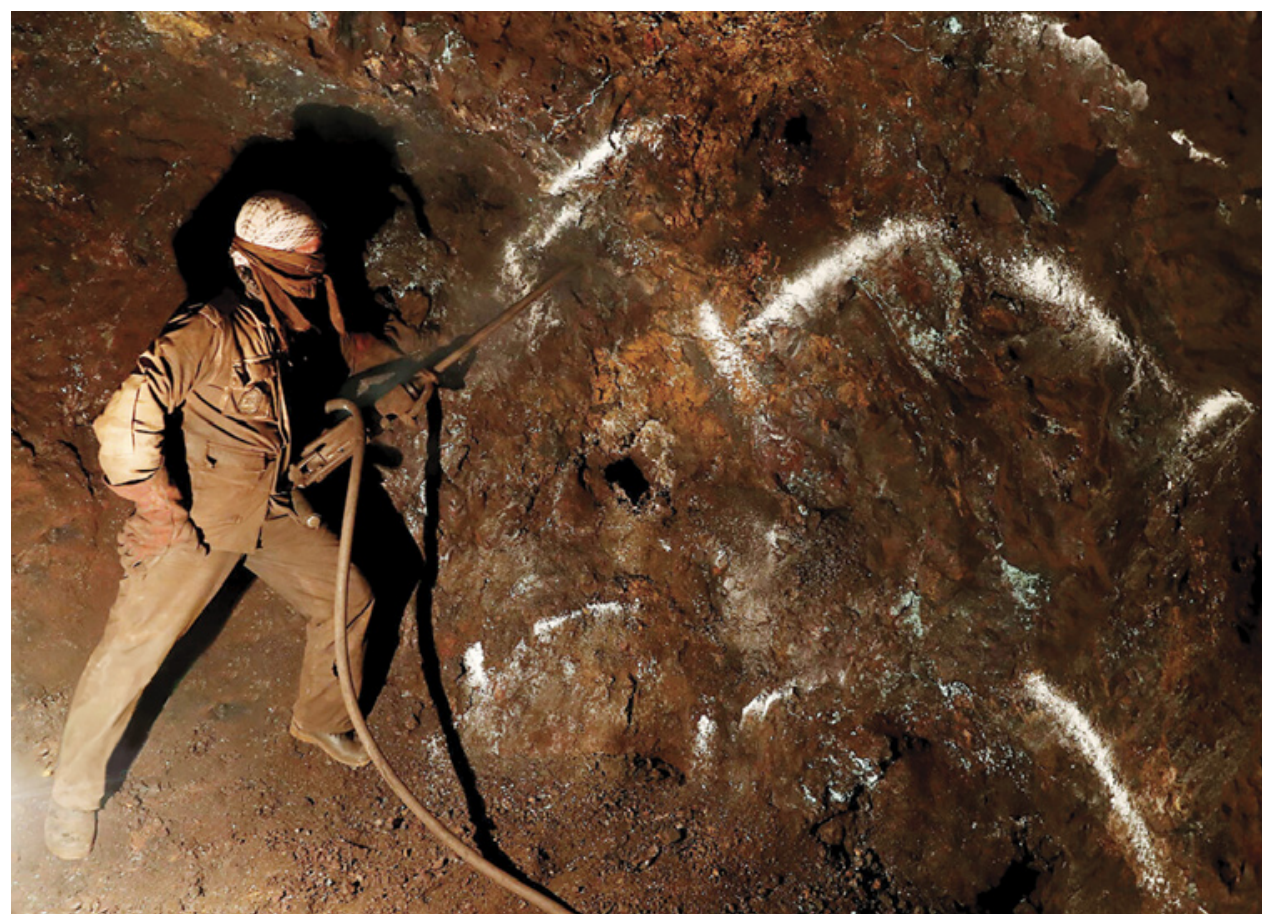

Figure 21. A drilling crew prepares to dig a blast hole. Photo by $M$. Bakhshandeh Zahmati.

mountain's surface and the mine, air flows through and creates natural ventilation. In the wintertime, it is colder outside the mine than inside. Warm air is lighter than cold, so the warm air rises through the shafts, drawing in fresh, cold air. In the summertime, the cool air in the mine settles, drawing in warm air through openings.

After blasting, when the ventilation is not completed by the next morning, portable ventilators are sometimes used to speed up the process.

Figure 22. Compressed air tubes in the tunnels. Photo by R. Azizi.

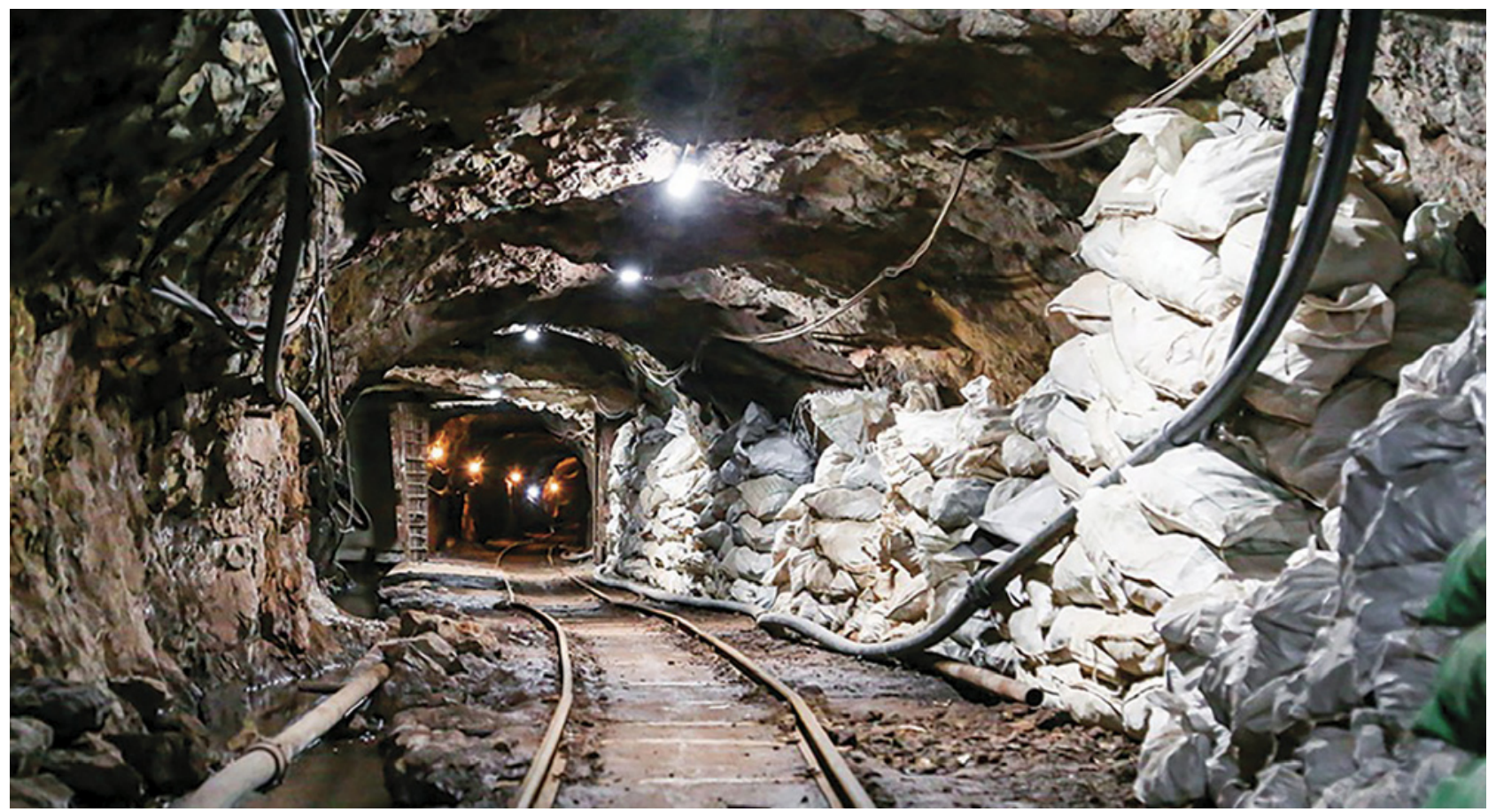




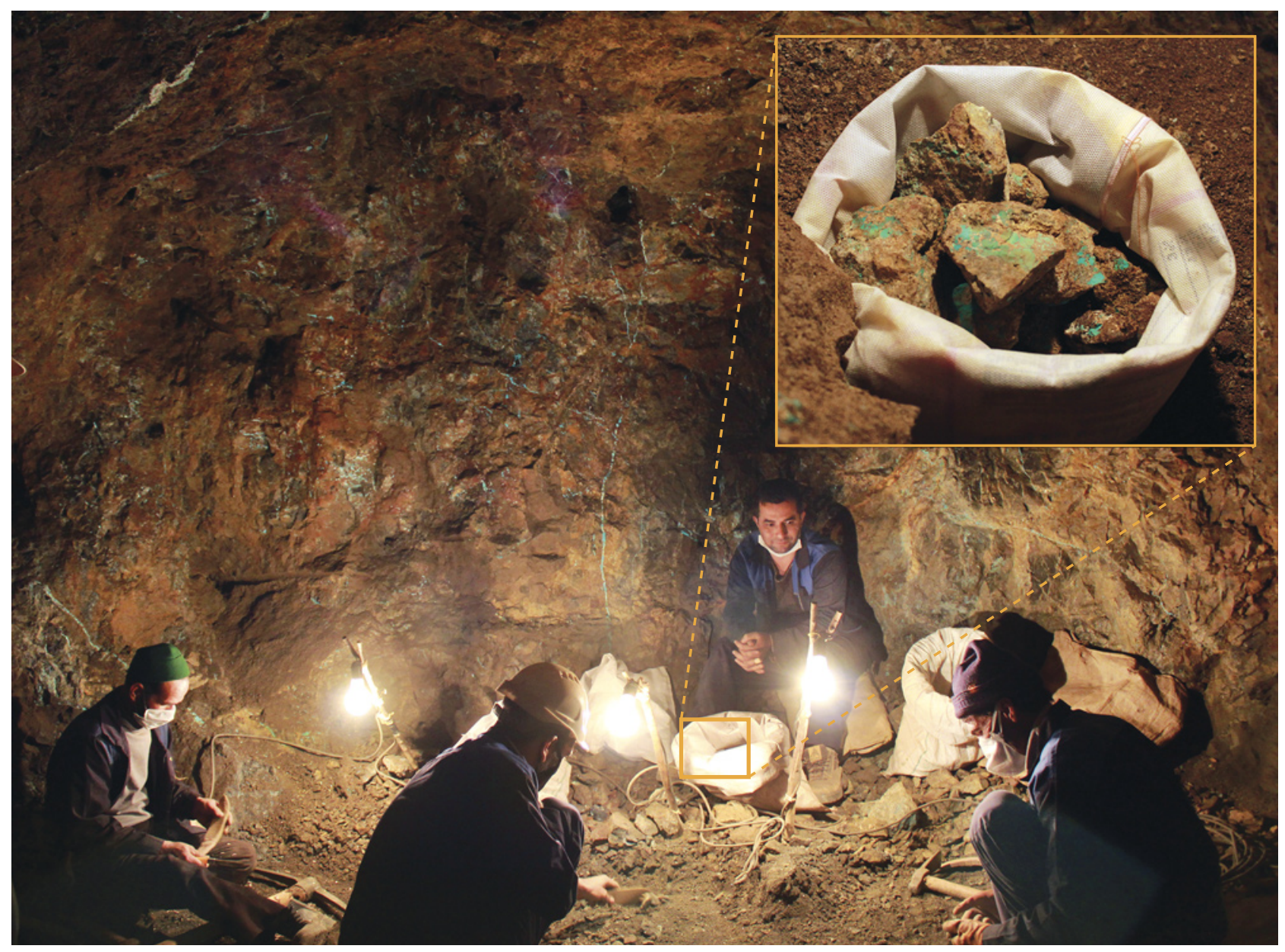

Figure 23. In the stopes, the supervisor watches from above as the miners sort turquoise. Photos by B. Shirdam.

Working Area. The miners work in groups, each of which is responsible for a stope. These groups usually have three to five people (figure 23), plus a supervisor who oversees them as they sort, classify, and cob the extracted turquoise in situ. The turquoise is sorted and classified based on its color, quality, vein thickness, shape, and toughness and then placed in bags to be transported to the mine's storeroom.

Although waste rocks are removed through shafts and by wagons (figure 24), the turquoise bags are carried out by miners themselves to avoid any unnecessary damage. All tunnels and their access drifts have rail tracks. Once the wagons are filled with waste rocks, they are hauled out by locomotive and sent to a dump.

Figure 24. At the Dom tunnel's entrance, the wagons are returned to the mine after emptying the waste. Photo by B. Shirdam.

\section{TURQUOISE PRODUCTION}

Among Iran's three main turquoise deposits, only the Neyshabur mine is dedicated to turquoise pro-

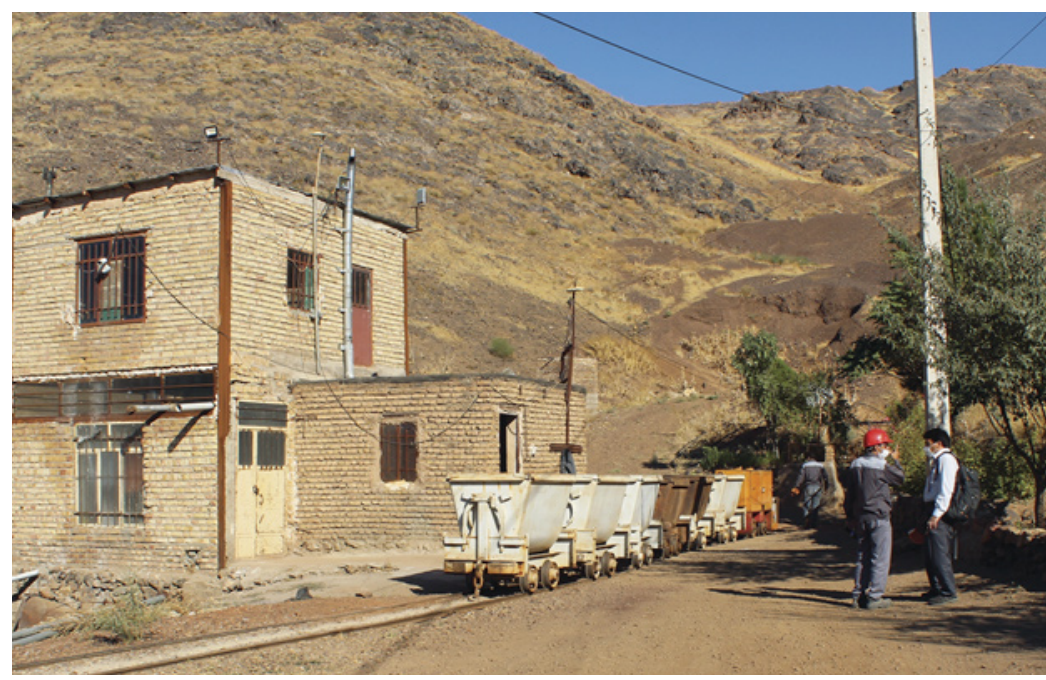



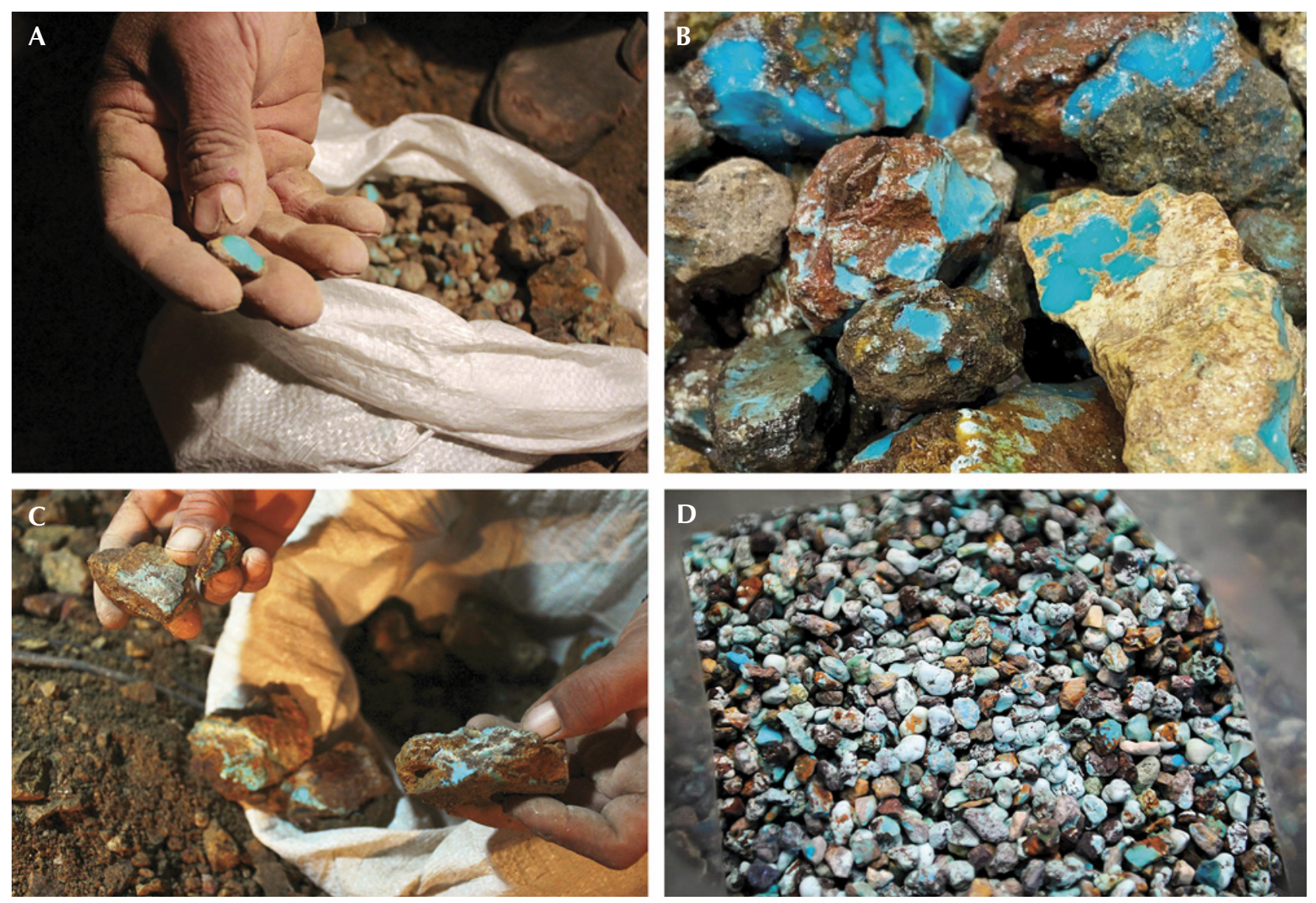

Figure 25. The four major quality levels of rough turquoise production from Neyshabur: turquoise nuggets $(A)$, turquoise with the host rock attached (B), chalky turquoise (C), and turquoise chips (D). Photos by B. Shirdam.

duction. Baghu turquoise is from the Kuh Zar mine, a gold and copper deposit, and Shahr-I Babak turquoise comes from the Meiduk mine, a porphyry copper deposit. The mining strategies at Kuh Zar and Meiduk are focused on the extraction of gold and copper, respectively, rather than turquoise. Despite the fine color of Baghu turquoise, the Kuh Zar mine currently reports no official production of turquoise. On the other hand, the Meiduk open-pit mine is working with the Shahr-I Babak turquoise cooperative to manage the turquoise extracted in the process of copper mining. Open-pit mining has caused an unstable turquoise yield. When there is a turquoise vein on one of the horizontal levels known as benches, the mine can produce an average of three tons per month, but otherwise there could be no production for months. More information on the Kuh Zar and Meiduk mines will be published in subsequent reports.

With more than 200 workers, an average production of four tons of rough turquoise per month, and an annual production of 40 to 42 tons, Neyshabur is
Iran's largest turquoise mine. Although the Main tunnel is the largest, as shown in table 2, more than $70 \%$ of the mine's turquoise comes from the Zahk tunnel.

Mine to Market. Turquoise Quality. Rough turquoise from Neyshabur is classified into four categories based on color, porosity, shape, and size.

Type I: Turquoise nuggets and slabs. Nuggets and slabs are the result of cavities and veins filled by turquoise. These are quite compact, usually flawless, and have been separated from the host rock during extraction (figure 25A). Nuggets and slabs display even color and can produce high-end finished turquoise.

Color is divided into three grades according to saturation. The first grade offers the most vivid colors. A second grade, called "half color"10 among locals, shows a less saturated blue and green compared to

10"Nim rang" in Persian. 
the first grade, while the third grade has a pale to white hue. It should be noted that the classification of turquoise color is a subjective matter and varies depending on trade, culture, fashion trends, supply, and personal opinion (Lowry and Lowry, 2010). These three color grades for type I turquoise apply for all rough turquoise categories.

Type II: Turquoise with the host rock attached. Turquoise veins, slabs, and nuggets that are sold with the host rock attached fall into this category (figure 25B). If the vein or seam is thick and carries an even and vivid color, it would easily rival the first grade of turquoise. A spiderweb pattern is the result of cutting this type of turquoise.

Type III: Chalky turquoise. This comes in light to pale blue, green, and white colors and in various sizes (figure $25 \mathrm{C}$ ). The material is porous and requires treatment. Depending on porosity and color, chalky turquoise undergoes a different process for stabilizing and color enhancement.

Type IV: Turquoise chips. After sorting and packing the rough turquoise in bags, some small pieces are left that have been broken, either during extraction or transport (figure 25D). These pieces that vary in color and quality are sold as chips and often used for turquoise inlay (e.g., figure 29).

It is important to mention that the Neyshabur mine does not apply any treatment and only sells the stones in their natural form. All treatments are applied in lapidary and turquoise inlay workshops.

Auctions. Whenever a certain amount of turquoise has been accumulated, the Neyshabur cooperative sends out a call for sale and holds an auction in the mine's yard (figure 26). Bags of turquoise are brought out, and a base price is offered based on the general

TABLE 2. Rough turquoise production of the Neyshabur mine in 2020.

\begin{tabular}{cc}
\hline Tunnel & Production $(\mathrm{kg})$ \\
\hline Main & 5,103 \\
Dom & 6,884 \\
Zahk & 30,315 \\
Total & 42,302 \\
\hline
\end{tabular}

quality of the raw material. Finally, the auction begins, and each bag is sold to the highest bidder. The cooperative's auctions are limited, usually holding three to four sessions per year.

The main purchasers of turquoise at these auctions are lapidaries, jewelry companies, and gemstone traders from Mashhad, Neyshabur, and Esfahan. Local lapidary workshops from $\mathrm{Ma}^{\prime}$ adan village have access to a set share of rough turquoise annually that can be purchased at a lower price without participating in auctions.

Turquoise Lapidary and Products. Although the art of cutting and polishing turquoise has a long history in Iran (Vidale and Lazzari, 2016; Hole et al., 1969), 


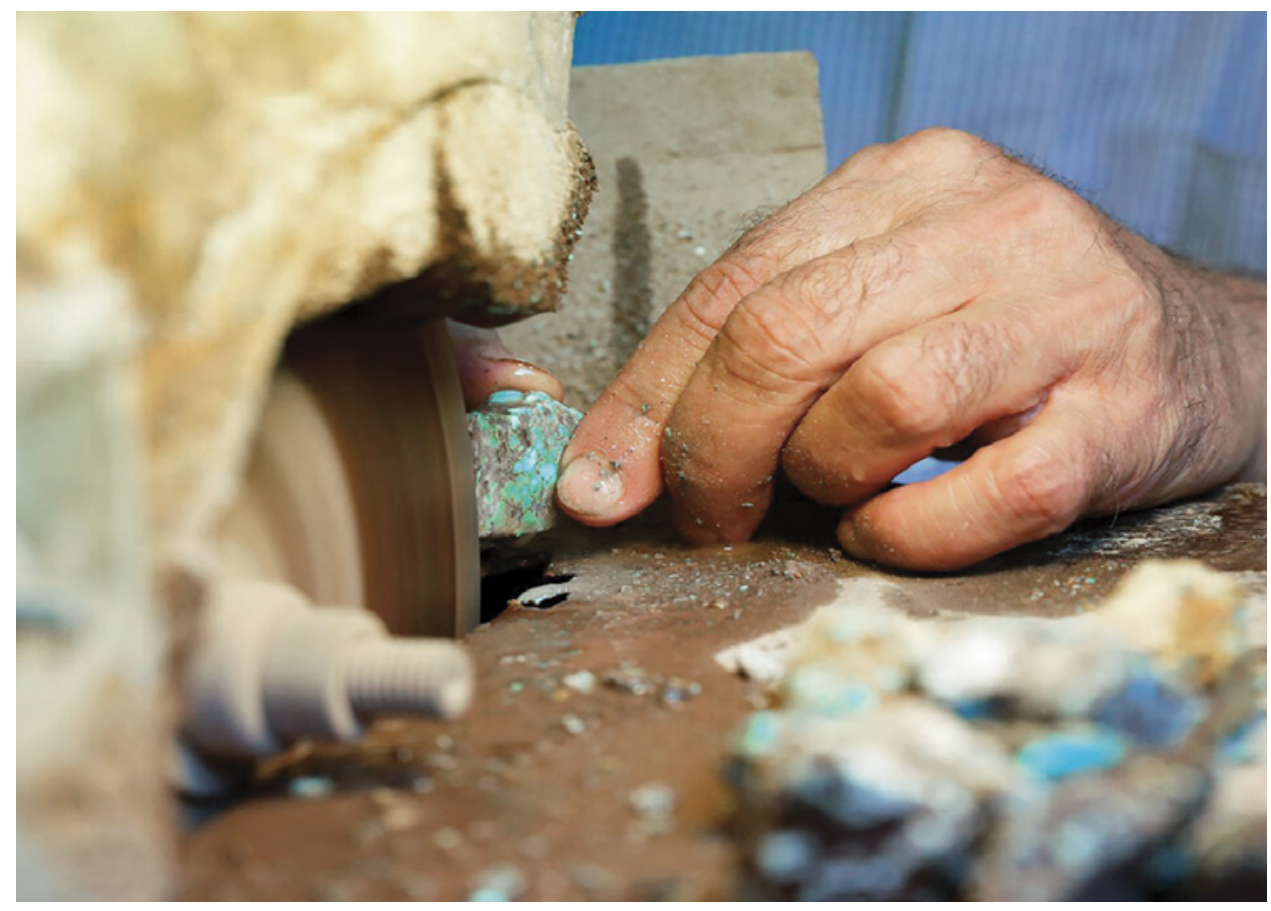

Figure 27. Slabbing rough turquoise in a lapidary workshop in Mashhad. Photo by $M$. Bakhshandeh.

the lapidary industry has grown in recent decades. More than 300 lapidary workshops have been established in Ma'adan village and the city of Neyshabur.

Mashhad, Tehran, Esfahan, and Neyshabur are the main centers for Iranian turquoise cutting, and they also have an active export market due to tourism and international flights. Most of the foreign clients are from Singapore, Kuwait, the United Arab Emirates, and Spain (Ahmadi et al., 2018). Yet it is important to mention that Iranian turquoise does not occupy a large portion of the global market.

About $60 \%$ of the yield from Neyshabur requires treatment. Unless the slabs and veins are very thin, the first color grade of turquoise from categories I and II does not require any treatment and lends itself to cutting and polishing without enhancement (figure 27). The second color grade may require treatment, depending on the cutter's judgment. Chalky turquoise, on the other hand, will break unless it is stabilized. While the idea of wearing untreated turquoise may sound appealing, exposure to chemicals, oils, perfume, sweat, and even sunlight and heat can cause its color to change. As traders in Iran put it, the turquoise will "die."

Since turquoise is an opaque gemstone, the cutting styles are limited. While faceting is an option,

Figure 28. Neyshabur turquoise $(12 \times 18 \mathrm{~mm})$ with a spiderweb pattern and framed with diamond accents, set in gold. Courtesy of Taktala Jewelry, Tehran. cabochon cutting has always been standard, even in recent jewelry designs (figure 28).

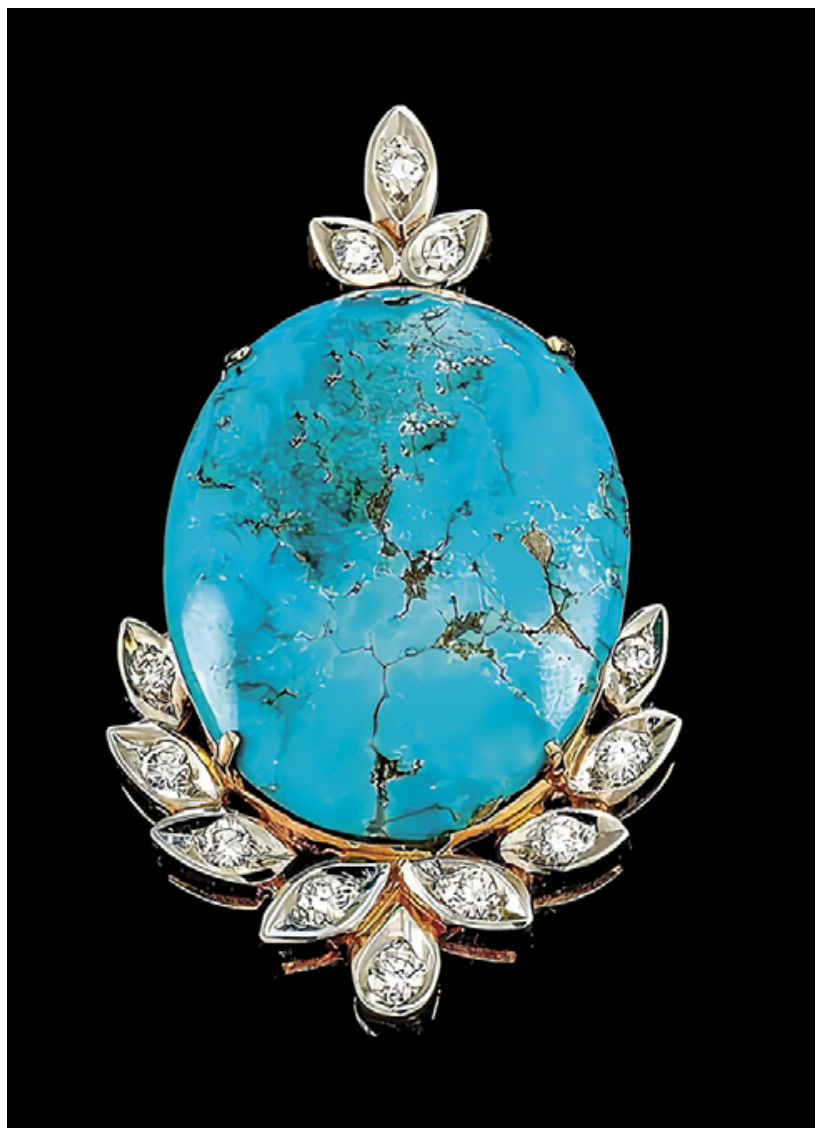




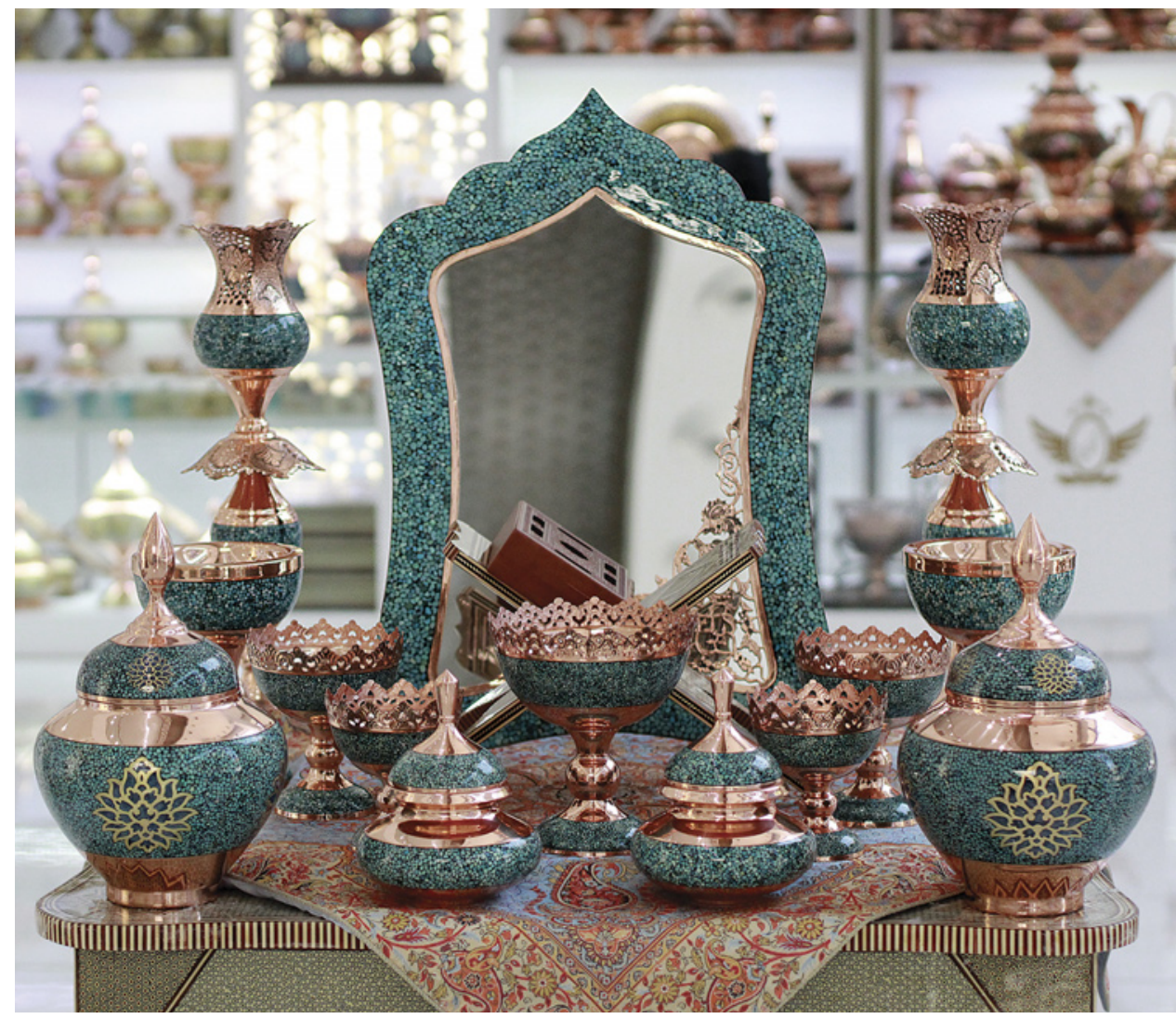

Figure 29. Turquoise inlay on copper handicrafts housed in the Aghajani Gallery, Tehran. Photo by $B$. Shirdam.
The mine also yields turquoise chips that are widely used in Iran for inlay. This handicraft, which originated in the city of Mashhad, is done by placing the chips in a mosaic pattern on the surface of plates, dishes, ornaments, decorative objects, and wall art (figure 29).

\section{CONCLUSIONS}

The site visit conducted in 2020 (figure 30) suggests that with three tunnels extracting an average of 40 tons per year, the mine is in fact quite active and still expanding. While turquoise evaluation is based on quality rather than geographic origin, the vivid colors and

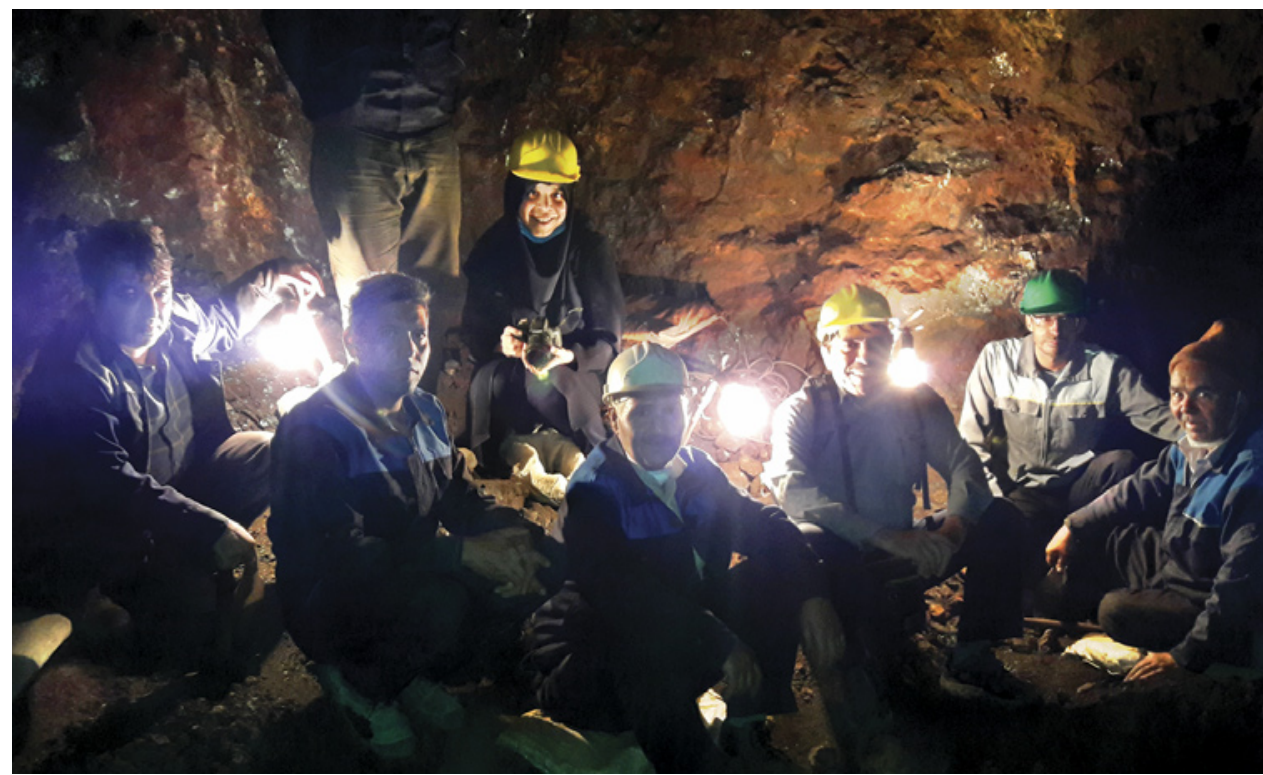

Figure 30. Author B. Shirdam (in the background) with miners in the Sabz tunnel. Photo by $R$. Shirdam. 


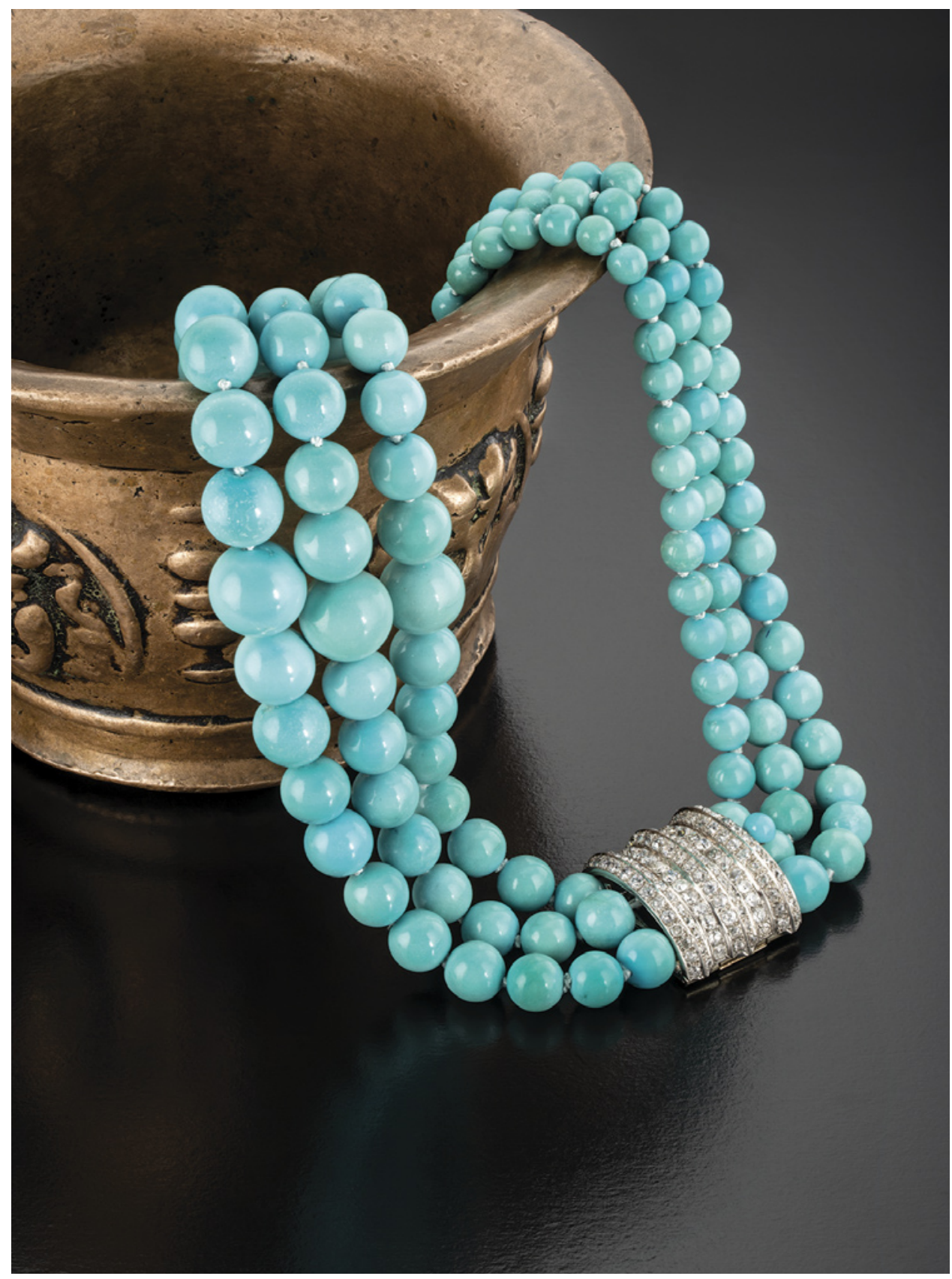

Figure 31. This Persian turquoise necklace designed by Suzanne Belperron, also shown on the cover of this issue, contains graduated beads measuring 6.3-14.68 $\mathrm{mm}$ and $a$ diamond clasp. Photo by Robert Weldon/GIA; courtesy of Sima G. Ltd., New York.

untreated nature of cut turquoise from the Neyshabur mine have been often found alluring (figure 31).

Despite the Neyshabur mine's productivity and tradition, this turquoise has yet to find its place in the global market. It has been plagued by claims that the mine is closing. Also, the generic term "Persian turquoise" has been hindered by inconsistent quality and pricing standards, causing some customers to question the product. Although most turquoise in the global market is either stabilized or treated, Iranian traders insist on focusing on untreated turquoise.
While the untreated version of the gemstone may be important to some customers, its high price, limited quantity, and sensitivity to chemicals are a drawback for others. In recent years many private companies in Iran have focused on treatment, improving the quality of second and third color grade material to produce commercial-quality turquoise for trading in the domestic and global market.

With a cohesive marketing and pricing strategy, turquoise from Neyshabur and other Iranian mines could once again compete in the global market. 


\section{ABOUT THE AUTHORS}

Ms. Shirdam is a PhD candidate, Dr. Shen (corresponding author) is a distinguished professor, and Dr. Yang is a professor, at the Gemmological Institute, China University of Geosciences in Wuhan. Dr. Mokhtari is a professor of geology at the University of Neyshabur in Neyshabur, Iran. Dr. Fazliani is managing director of the Neyshabur turquoise mine cooperative.

\section{ACKNOWLEDGMENTS}

The authors sincerely thank the Neyshabur turquoise mine cooperative and all the hardworking miners and experts, especially Mr. Reza Farkhari, the mine's technical manager, for their kind help and support during several visits.

\section{REFERENCES}

Ahmadi R., Karimi A., Hajipour A. (2018) Investigation of the status of turquoise mineral industry in Iran and its global export. Eghtesad Asia, No. 561, pp. 9-11 (in Persian).

Bazin D., Hübner H. (1969) Copper deposits in Iran. Geological Survey of Iran, Tehran.

Eshbak P., Malekzadeh Shafaroudi A., Karimpour M.H. (2019) Petrography, geochemistry, $\mathrm{U}-\mathrm{Pb}$ dating, $\mathrm{Sr}-\mathrm{Nd}$ isotopes, and petrogenesis of Jalambadan igneous rocks, NW Sabzevar. Geosciences, Vol. 28, No. 112, pp. 167-180.

Ghiasvand A., Karimpour M.H., Malekzadeh Shafaroudi A., Hidarian Shahri M.R. (2017) Age and origin of subvolcanic rocks from NE Iran: Link between magmatic "flare-up" and mineralization. Chemie der Erde, Vol. 78, No. 2, pp. 254-267, http://dx.doi.org/10.1016/j.chemer.2017.12.002

Hole F., Flannery K.V., Neely J.A. (1969) Prehistory and Human Ecology of the Deh Luran Plain: An Early Village Sequence from Khuzistan, Iran. University of Michigan Press. http://dx.doi.org/10.3998/mpub.11395036
Lowry J.D., Lowry J.P. (2010) Turquoise: The World Story of a Fascinating Gemstone. Gibbs Smith, Layton, Utah.

Spies O., Lensch G., Mihm A. (1984) Geochemistry of the postophiolitic tertiary volcanics between Sabzevar and Quchan/NE Iran geodynamic project (geotraverse) in Iran. Geological Survey of Iran, Report 51, pp. 248-264.

Vidale M., Lazzari A. (2016) Lapis Lazuli Bead Making at Shahr-i Sokhta: Interpreting Craft Production in an Urban Community of the 3rd Millennium BC, Serie Orientale Roma, Vol. 6, Antilia.

Vinogradov A.V., Lopatin S.V., Mamedov E.D. (1966) The turquoise of the Kyzyl-Kum. Soviet Anthropology and Archeology, Vol. 4, No. 4, pp. 11-28, http://dx.doi.org/10.2753/AAE10611959040411

Weisgerber G. (2004) The turquoise mines at Nishapur. In T. Stollner, R. Slotta, and A. Vatandoust, Eds., Persian Antiques Splendor (Mining Crafts and Archaeology in Ancient Iran). Deutsches Bergbau-Museum Bochum, Bochum, Germany, pp. 502-509.

\section{For online access to all issues of GEMS \& GEMOLOGY from 1934 to the present, visit:}

